THORACIC TRAUMA AND CRITICAL CARE 


\title{
THORACIC TRAUMA AND CRITICAL CARE
}

\author{
edited by
}

\author{
Riyad Karmy-Jones, MD \\ Avery Nathens, MD \\ Eric J. Stern, MD \\ Harborview Medical Center \\ University of Washington \\ Seattle, Washington
}

Springer-Science+Business Media, B.V . 


\section{Library of Congress Cataloging-in-Publication Data}

Thoracic trauma and critical care / edited by Riyad Karmy-Jones, Avery Nathens, Eric J. Stern.

p. ; cm.

Includes bibliographical references and index.

$$
\text { ISBN 978-1-4613-5407-9 ISBN 978-1-4615-1127-4 (eBook) }
$$

DOI 10.1007/978-1-4615-1127-4

1. Chest--Wounds and injuries. 2. Chest--Surgery. 3. Respiratory distress syndrome. 4. Critical care medicine. I. Karmy-Jones, Riyad. II. Nathens, Avery III. Stern, Eric J.

[DNLM: 1. Thoracic Injuries--therapy. 2. Critical Care--methods. 3. Infection Control. 4. Respiratory Distress Syndrome, Adult--therapy. 5. Thoracic Surgical Procedures. 6. Ventilators, Mechanical. WF 985 T4873 2002]

RD536 .T4825 2002

617.5'4--dc21

Copyright (C) 2002 by Springer Science+Business Media Dordrecht Originally published by Kluwer Academic Publishers in 2002

Softcover reprint of the Hardcover 1st edition 2002

All rights reserved. No part of this work may be reproduced, stored in a retrieval system, or transmitted in any form or by any means, electronic, mechanical, photocopying, microfilming, recording, or otherwise, without the written permission from the Publisher, with the exception of any material supplied specifically for the purpose of being entered and executed on a computer system, for exclusive use by the purchaser of the work.

Permission for books published in Europe: permissions@wkap.nl Permissions forbooks published in the United States of America:permissions@wkap.com

Printed on acid-free paper.

The Publisher offers discounts on this book for course use and bulk purchases. For further information, send email to melissa.ramondetta@wkap.com. 
To my wife, Lorie, who every day demonstrates concentration, courage and compassion-RKJ

To my wife, Jane, whose enduring patience has made this book possible-AN

To my colleagues at Harborview who strive daily (and nightly) to care for those less fortunate than ourselves and to my beautiful wife, Karen who supports me in all my endeavors.-EJS 


\section{CONTRIBUTORS}

\section{Blaine Achen MD}

Resident, Department of Anesthesia

University of Alberta

Edmonton, Alberta

Richard K. Albert, M.D.

Professor

Pulmonary and Critical Care

Medicine

Denver Health Medical Center

Denver, CO

\section{Scott K. Alpard MD}

Division of Cardiothoracic Surgery

University of Texas Medical Branch

Galveston, Texas

Gregory J. Bauer, MD

Assistant Professor of Surgery

Cornell-Weill Medical School

New York, NY

\section{Walter L. Biffl, MD,FACS}

Assistant Professor of Surgery

Chief, Pediatric Trauma

Denver Health Medical Center

University of Colorado Health

Sciences Center

Tyler Black MD

Department of Surgery

University of Alberta

Edmonton, $\mathrm{AB}$

\section{Robert D. Bloch MD}

Assistant Professor

Section of Interventional Radiology

Department of Radiology

University of Washington

Seattle, WA

\section{Michael E. Boczar, DO}

Department of Emergency Medicine

University of Michigan School of

Medicine

Hurley Medical Center

Flint, Michigan
John J. Borsa, MD, FRCPC

Assistant Professor - Interventional

Radiology

University of Washington Medical

Center

Seattle, WA

Edward Boyle, Jr., MD

Attending Cardiothoracic Surgeon

St. Charles Medical Center

Heart Institute of the Cascades

Bend, OR

Susan I. Brundage, MD, MPH, FACS

Assistant Professor of Surgery

The Michael E. DeBakey Department

of Surgery

Baylor College of Medicine

Houston, Texas

Eileen M. Bulger, MD

Assistant Professor

Department of Surgery

Harborview Medical Center

Seattle, WA

Yvonne M. Carter MD

Chief Resident

Department of Surgery

Harborview Medical Center

Seattle, WA

Carole Cornejo MD

Assistant Professor

Department of Surgery

Harborview Medical Center

Seattle, WA

Joseph Cuschieri, MD

Assistant Professor

Department of Surgery

University of Cincinnati

Cincinnati, $\mathrm{OH}$ 
Steven Deem MD

Associate Professor, Anesthesiology and Medicine (adjunct, Pulmonary and Critical Care)

University of Washington,

Harborview Medical Center, Seattle, WA

\section{Daniel J. DiBardino MD}

Surgical Resident

The Michael E. DeBakey Department of Surgery

Baylor College of Medicine

Houston, Texas

\section{Robert DuBose MD}

Surgical Resident

University of Washington

Seattle, WA

\section{Thomas R. Eubanks, DO}

Assistant Professor

Department of Surgery

University of Washington

Seattle, WA

Samir M. Fakhry MD, FACS.

Associate Chair for Research and

Education

Chief, Trauma Services

Inova Fairfax Hospital

Falls Church, VA

Clinical Professor of Surgery

Georgetown University

Washington, DC

\section{Mitchell S. Farber MD, FACS}

Attending Surgeon

Hurley Medical Center

Flint, MI

Assistant Professor

Department of Surgery

Michigan State University

\section{Adam Goldin MD}

Chief Resident

Department of Surgery

University of Washington Medical

Center

Seattle, WA

\section{Larry M. Gentilello MD, FACS}

Associate Professor

Harvard Medical School

Chief, Division of Trauma and

Critical Care

Beth Israel Deaconess Medical Center

Boston, MA

Nicole Gibran MD, FACS

Associate Professor

University of Washington Burn

Center

Harborview Medical Center

Seattle, WA

David Gourlay MD

Research Fellow,

Division of Trauma

University of Washington,

Seattle, WA

Mystan A. Gurkin MD

Department of Surgery

Henry Ford Hospital

Detroit, MI

\section{R. Alan Hall MD}

Attending Surgeon

Division Cardiothoracic Surgery

Virginia Mason Medical Center

Seattle, WA

Robert Harrington, MD

Associate Professor

Infectious Diseases

University of Washington

Harborview Medical Center

Seattle, WA 
David M. Heimbach, MD,FACS

Professor, Department of Surgery

University of Washington

Seattle, WA

H. Mathilda Horst, MD, FACS, FCCM

Chief, SICU

Henry Ford Hospital

Detroit, MI

James H. Holmes IV, MD

Chief Resident

Virginia Mason Medical Center

Seattle, WA

\section{Eric Hoffer MD}

Associate Professor, Department of

Radiology, University of Washington

Co-Director, UW AMC Endovascular

Services Program

Associate Director of Radiology,

Harborview Medical Center

\section{F. Frank Isik MD, FACS}

Associate Professor, Division of

Plastic Surgery

Department of Surgery

University of Washington School of Medicine

Jay A. Johannigman, M.D. FACS

Associate Professor

Chief, Division of Trauma

Department of Surgery

University of Cincinnati

Cincinnati, $\mathrm{OH}$

\section{Divya Kapoor MD}

Department of Internal Medicine

University of Utah

Salt Lake City, UT
Riyad Karmy-Jones MD, FACS,FRCS(C),FCCP,FAHA

Chief, Thoracic Surgery

Harborview Medical Center

Associate Professor Surgery

Division of Cardiothoracic Surgery

University of Washington

Seattle, WA

\section{Lillian S Kao MD}

Assistant Professor

Department of Surgery

University of Texas

Houston, TX

Robert R. Kempainen, MD

Assistant Professor

Division of Allergy, Pulmonary and

Critical Care Medicine

University of Minnesota

Minneapolis, MN

Nadeem A. Khan, M.D., M.P.H.

Clinical Research Fellow

Trauma Services

Inova Fairfax Hospital

Falls Church, VA

\section{Andrew W Kirkpatrick MD}

FRCS(C), FACS

Section of Trauma Services

Vancouver General Hospital,

Vancouver, Canada

John B. Kortbeek MD, FRCSC,FACS

Director Trauma Services

Calgary Health Region

Clinical Associate Professor

Department of Surgery

University of Calgary

Calgary, AB

Kurt Kralovich MD, FACS

Division of Trauma/SICU

Henry Ford Hospital

Detroit, MI 
David H. Lewis MD

Associate Professor

Director Nuclear Medicine

Harborview Medical Center

Seattle, WA

Donald E. Low,MD,FACS,FRCS(C)

Section of General, Thoracic Surgery

Virginia Mason Medical Center

Seattle, Washington

\section{Ronald V. Maier MD, FACS}

Professor and Vice-Chairman

Department of Surgery

University of Washington

Surgeon-in-Chief

Harborview Medical Center

Seattle, WA

Cairen J. McNamee MD, FRCS(C)

Consultant, Thoracic Surgery

University of Alberta

Edmonton, Alberta

Mark H. Meissner, MD, FACS

Associate Professor

Department of Surgery

Harborview Medical Center

University of Washington School of

Medicine

Ernest E. Moore, MD, FACS

Chief, Department of Surgery

Denver Health Medical Center

Professor and Vice-Chairman of

Surgery

University of Colorado Health

Sciences Center

Jeffrey Monson MD

Chief Resident

Department of Surgery

University of Washington

Seattle, WA
Michael S. Mulligan MD

Chief, Lung Transplant Program

Division of Cardiothoracic Surgery

University of Washington

Seattle, WA

Avery Nathens MD, PhD, FRCSC,FACS

Assistant Professor

Chief, SICU

Harborview Medical Center

Seattle. WA

Margaret J. Neff MD, MSc

Assistant Professor of Medicine

Director, Critical Care Research

Division of Pulmonary \& Critical

Care

Harborview Medical Center

Seattle, WA

Lindsey A. Nelson MD

Department of Surgery

University of Cincinnati

Cincinnati, $\mathrm{OH}$

Savvas Nicolaou MD, FRCP(C)

Department of Radiology, Vancouver

General Hospital, Vancouver, Canada

Stephen Nichols, MD, FACS

Assistant Professor

Chief, Vascular Surgery

Harborview Medical Center

Seattle, WA

Ram Nirula MD, MPH, FACS

Fellow, Trauma/SICU

Department of Surgery

Harborview Medical Center

University of Washington School of

Medicine

Dinh Nguyen MD

Trauma/SICU Fellow

Hurley Medical Center

Flint, MI 
David P. O'Brien, M.D

Department of Surgery

University of Cincinnati

Cincinnati, $\mathrm{OH}$

Farouck N. Obeid MD, FACS

Chief, Department of Trauma/SICU

Hurley Medical Center

Flint, MI

Professor

Department of Surgery

Michigan State University

Donald Oxorn MD, CM, FRCPC,

FACC

Associate Professor of Anesthesiology

Adjunct Associate Professor of

Medicine

University of Washington School of

Medicine

Seattle, Washington

Manesh Parikshak, MD

Trauma/Critical Care Fellow

Henry Ford Hospital

Detroit, Michigan

David J. Pierson MD

Proffessor, Pulmonary and Critical

Care Medicine

Medical Director, Respiratory Care

Harborview Medical Center

Seattle, WA

\section{Timothy H. Pohlman MD, FACS}

Professor

Department of Surgery

Harborview Medical Center

University of Washington School of Medicine

Emanuel P. Rivers, MD, MPH, FCCM

Departments of Emergency Medicine and Surgery

Case Western Reserve University

Henry Ford Hospital

Detroit, Michigan
Matthew Rosengart MD

Chief Resident

University of Washington

Seattle, WA

\section{Scott Sattler MD}

Chief Resident

Department of Surgery

University of Washington

Seattle, WA

Romualdo J. Segrola, Jr., MD

Fellow, Cardiothoracic Surgery

University of Minnesota

Minneapolis, MN

David V. Shatz MD, FACS

Associate Professor

Department of Surgery

University of Miami School of

Medicine

Miami, FL

Scott E. Sinclair, M.D.

Acting Clinical Instructor

Pulmonary and Critical Care

Medicine

University of Washington

Seattle, WA

\section{Shawn J. Skerrett MD}

Associate Professor

Pulmonary and Critical Care

Medicine

University of Washington

Harborview Medical Center

Seattle, WA

Victor J. Sorensen MD, FACS

Attending Surgeon

Trauma/SICU

Hurley Medical Center

Flint, MI

Assistant Professor

Department of Surgery

Michigan State University 
Eric Stern MD

Professor

Chief Thoracic Radiology

Harborview Medical Center

University of Washington

Seattle, WA

Gregory D. Trachiotis, MD, FACS

Associate Professor of Surgery

Vice-Chief, Division of

Cardiothoracic Surgery

The George Washington University

Medical Center

Kristin Wagner, MD

Chief Resident, Department of

Surgery

The George Washington University

Medical Center

Washington, DC

Cheryl A. White MD, PhD

Senior Resident

Division of Plastic Surgery

Department of Surgery

University of Washington School of

Medicine

Douglas E. Wood, MD, FACS

Associate Professor

Chief, Section of Thoracic Surgery

The UW Endowed Chair in Lung

Cancer Research

Division of Cardiothoracic Surgery

University of Washington

Seattle, WA

\section{Stewart Worrell MD}

Department of Surgery

University of Washington School of Medicine

John D Urschel, MD, FRCSC,

FACS, FRCSEd

Associate Professor

Department of Surgery

McMaster University,

Hamilton, Ontario
Eric Valliéres, MD, FRCS(C)

Associate Professor

Division of Cardiothoracic Surgery

University of Washington

Seattle, WA

Curtis F. Veal, Jr., M.D., FACP, FCCP

Medical Director, Kindred Hospital-

Seattle

Co-director, Critical Care Services, Swedish Health Systems

Clinical Associate Professor of Medicine, University of Washington

Joseph B. Zwischenberger

MD,FACS

Professor of Surgery, Medicine and

Radiology

Director General Thoracic Surgery and ECMO program

University of Texas Medical Branch

Galveston, Texas 


\section{CONTENTS}

\section{Underlying Principles}

1.1 Trauma Scores: Recent Advances: Samir M. Fakhry, Nadeem A. Khan

1.2 Care of the Multiple Injured Patient with Thoracic Trauma: Farouck N. Obeid, Mitchell S. Farber, Dinh Nguyen

1.3 Assessing adequacy of resuscitation: Ram Nirula, Larry Gentillelo

1.4 Reperfusion Injury: Timothy H. Pohlman

\section{Thoracostomy, Thoracoscopy and Thoracotomy}

2.1 Tube Thoracostomy: Joseph Cuschieri

2.2 Incisions and approaches: Mitchell S. Farber, Farouck N. Obeid

2.3 ER-Thoracotomy: Adam Goldin, Riyad Karmy-Jones, Carole Cornejo

2.4 Urgent Non-ER Thoracotomy: Mathew Rosengart, Riyad Karmy-Jones

2.5 Abbreviated Thoracotomy; The Evolving Role of Damage Control in Thoracic Trauma: Daniel J. DiBardino, Susan I. Brundage.

2.6 Transmediastinal Gunshot Wounds:David V. Shatz, Romualdo J. Sergurola Jr.

2.7 Role of Thoracoscopy in Chest Trauma: Jeffrey Monson, Riyad Karmy-Jones

2.8 Management of Retained Hemothorax: David Gourlay

2.9 Thoracotomy for Medical Arrest: Michael E. Boczar, Emanuel P. Rivers

\section{Pulmonary and Airway Emergencies}

3.1 Lung Injuries: Kurt Kralovich

3.2 Tracheo-bronchial Injuries Douglas Wood

3.3 Traumatic Asphyxia: Joseph Cushieri

3.4 Pulmonary Blast Injury: Robert DuBose, Riyad Karmy-Jones

3.5 Inhalation Injury: Gregory J. Bauer, Nicole Gibran, David M. Heimbach

3.6 Thoracic Missile Embolism and Retained Bullets: John Kortbeek, Divya Kapoor, Riyad Karmy-Jones

3.7 Radiological Evaluation of Parenchymal Injuries: Eric Stern

3.8 Airway Obstruction: Douglas E. Wood

3.9 Complications of Lung Transplantation: Michael S. Mulligan

3.10Air Embolism: Donald Oxorn

3.11Massive Hemoptysis: Cairen J. McNamee, Tyler Black, Eric Vallieres, Riyad Karmy-Jones

3.12Tracheo-Inominant Artery Fistula: Blaine Achen,M.D., Cairen J. McNamee, M.D., Tyler Black, M.D.

3.13Hemoptysis Following Catheter Induced Ruptures of the Pulmonary Artery:

Cairen J. McNamee,Blaine Achen,Tyler Black,

3.14Re-expansion Pulmonary Edema: Kristin Wagner , Gregory D. Trachiotis

3.15Postpneumonectomy Pulmonary Edema: John Urschel

3.16The Sonographic Detection of Pneumothoraces: Andrew.W. Kirkpatrick MD, S. Nicolaou MD

\subsection{Chest Wall Trauma}

4.1 Pulmonary Contusion and Flail Chest: Medical Management: Scott Sattler, Ron Maier

4.2 Reconstruction of Complex Chest Wall Defects: Cheryl A. White, F. Frank Isik, $\mathrm{MD}$ 
4.3 Chest Wall Burns: Nichole Gibran

4.4 Chest Wall Hernia: Lillian S. Kao

4.5 Diaphragmatic Injuries: Victor J. Sorenson

\subsection{Esophageal Emergencies}

5.1 Caustic Injuries: Thomas Eubanks

5.2 Esophageal trauma and perforation: Lillian Kao and Riyad Karmy-Jones

\subsection{Cardiovascular Emergencies}

6.1 Blunt Cardiac Injury: Walter L. Biffl, Ernest E. Moore

6.2 Blunt Cerebrovascular Trauma: Lindsey A. Nelson, David P. O’Brien, Jay A. Johannigman,

6.3 Penetrating Cardiac Injury: Riyad Karmy-Jones, Stewart Worrell

6.4 Management of Great Vessel Injury : Stephen C. Nicholls

6.5 Blunt Aortic Injury: Diagnosis John Borsa

6.6 Operative Management Of Blunt Thoracic Aortic Injuries: Mathew Rosengart, Riyad Karmy-Jones

6.7 Non-operative Management of Blunt Thoracic Aortic Injury James H. Holmes IV, R. Alan Hall,, and Riyad C. Karmy-Jones

6.8 Blunt Aortic and Great Vessel Injuries: The Role of Endovascular Stent Rick Hoffer

6.9 Pharmacological Support of Shock: Steven Deem

6.10 Intra-aortic Balloon Pump: Edward Boyle Jr.

6.11 Cardiopulmonary Bypass: Riyad Karmy-Jones

6.12 Deep Venous Thrombosis: Prophylaxis and Treatment in the Critically Ill and Injured Patient: Mark H. Meissner

6.13 Management of Acute PE: Yvonne M. Carter MD, David Lewis MD, Robert Bloch, Riyad Karmy-Jones

6.14 Post-Operative Complications of Cardiovascular Surgery: Riyad C. KarmyJones

\subsection{Infections in the Critical Care Setting}

7.1 Diagnosis of ventilator associated pneumonia Shawn Skerret

7.2 Empyema: Jeffery Monson, Riyad Karmy-Jones

7.3 Necrotizing pneumonia: Robert Harrington

7.4 Surgical Management of Complex Parenchymal Infections: Jeffrey Monson, Riyad Karmy-Jones

7.5 Descending Necrotizing Mediastinitis Eric Vallieres

\subsection{Respiratory Intensive Care}

8.1 Ventilation: An Overview: Eileen M. Bulger

8.2 Adult Respiratory Distress Syndrome: Eileen M Bulger

8.3 High Frequency Ventilation: Manesh Parikshak, Mystan A. Gurkin, H. Mathilda Horst.

8.4 Pressure Control-Inverse Ratio Ventilation: Mystan A. Gurkin ,Manesh Parikshak, H. Mathilda Horst. 
8.5 Prone Ventilation in the Acute Respiratory Distress Syndrome: Scott E. Sinclair, Richard K. Albert.

8.6 ECMO in the surgical patient: Scott K. Alpard and Joseph B. Zwischenberger

8.7 Liquid Ventilation: Mathew Rosengart

8.8 The role of Nitric Oxide in Sepsis and Respiratory Failure: Margaret Neff

8.9 Evaluation and Management of Persistent Air Leaks in Trauma Patients:Robert Kempainan MD and David Pierson MD

8.10Surgical Lung Biopsy:Indications, Techniques, Outcomes and Controversies:

Donald E. Low, M.D.

8.11Fat Embolism: Eileen Bulger

8.12Timing of Long Bone Fracture Fixation in Patients with Blunt Thoracic Trauma:

Ram Nirula, Avery B. Nathens

8.13Acquired Neuromuscular Disorders in the Intensive Care Unit: Steven Deem

8.14Weaning the chronically ventilated patient: Curtis Veal

8.15Tracheostomy: Douglas Wood 